\title{
Research of a Visual Multifunction Control Lever
}

\author{
Hao Guo \& Wenjian Mei \& Zhaohui Zhen \\ State Grid Hunan Electric Power Company Live Working Center, Changsha, Hunan, 410007, China
}

Shuang Yang

Hunan Wuling Power Engineering Co. Ltd, Changsha Hunan 410000, China

Yang Long

State Grid Hunan Electric Power Company Live Working Center, Changsha, Hunan, 410007, China

\begin{abstract}
Due to the operating poison is far, the line of sight is not good, inconvenient operation is caused when using the operator lever, in addition, replacing insulator need to be replaced different functions pin puller. To solve the problems, this paper development a visual multifunction control lever and multifunction pin puller, operators can use the control lever control in the process of operation, and replace insulators by one time. The control lever is easy to use, and it can improve the efficiency and safety levels of live working.
\end{abstract}

KEYWORD: Control lever; visual; multifunctional; pin puller; image transmission equipment

\section{INTRODUCTION}

With the rapid development of China's power grid, the user's demand for power supply reliability is also getting higher and higher. In order to guarantee the stability of the power grid, live working will become an important technical means to protect the security and stability of the grid. The workers often use insulated operating lever to disassemble and fasten bolt, to fixed insulator and demolition pull $\mathrm{W}$ sales by living work. At present, due to the operating posion is far, the line of sight is not good, inconvenient operation is caused when using the old operator lever. In addition, replacing insulator need to be replaced different functions pin puller ( $\mathrm{Hu}$ Tao et al, 2006) $(\mathrm{Hu}$ $\mathrm{Yi}, 2004)$.This paper development a visual multifunction control lever and multifunction pin puller, operators can use the control lever control in the process of operation, and replace insulators by one time. The control lever is easy to use, and it can improve the efficiency and safety levels of live working.

\section{DEVELOPMENT OF VISUAL MULTIFUNTION CONTROL LEVER}

\subsection{Design directions}

According to the functional requirements, each function module of the operating lever can be designed, and finally, the test tool can meet the requirements. If the requirements are met, the field trial can be carried out. Specific design ideas as shown in Figure 1.

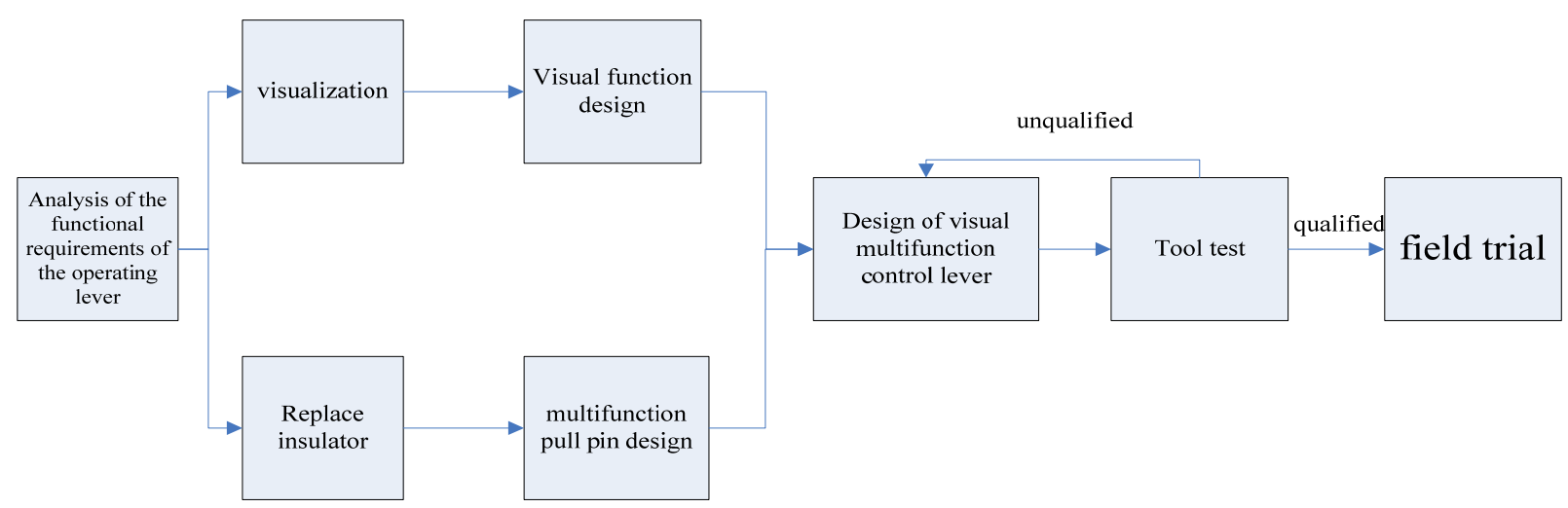

Figure1 Design directions 
monitor module and image

transmission system

module

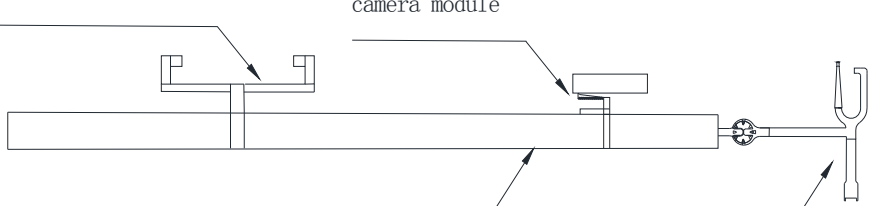

operating lever module

pull pin module

Figure 2 Integral structure diagram

Multifunction visual operating lever should include four modules: the operating lever body, camera module, image transmission system module, monitor module and multifunction pull pin module. The operating lever body adopts an insulating operating lever used for live working at present, the camera module is fixed on the front of the operating lever, and it can regulate the angle according to the needs of work. The monitor module is fixed on the rear section of the operating lever through the equipment support, and the camera module sends message to the monitor through the image transmission module. The front of the operating lever is provided with a universal tooth shaped connecting plate, which can be connected with a multifunctional pull pin module. The overall structure is shown in Figure 2.

\subsection{Visual function design based on image transmission system}

The visual function system of operating lever includes: camera module, image processing module, wireless module, and image receiving module and the monitor and control pin. The camera module gets video information which is converted it into data by the image processing module. The data is sent through the wireless transmission to the image control and receiving module which process the data to monitor, and realizes the visual function. The overall framework of the visual function was shown in the figure 3.

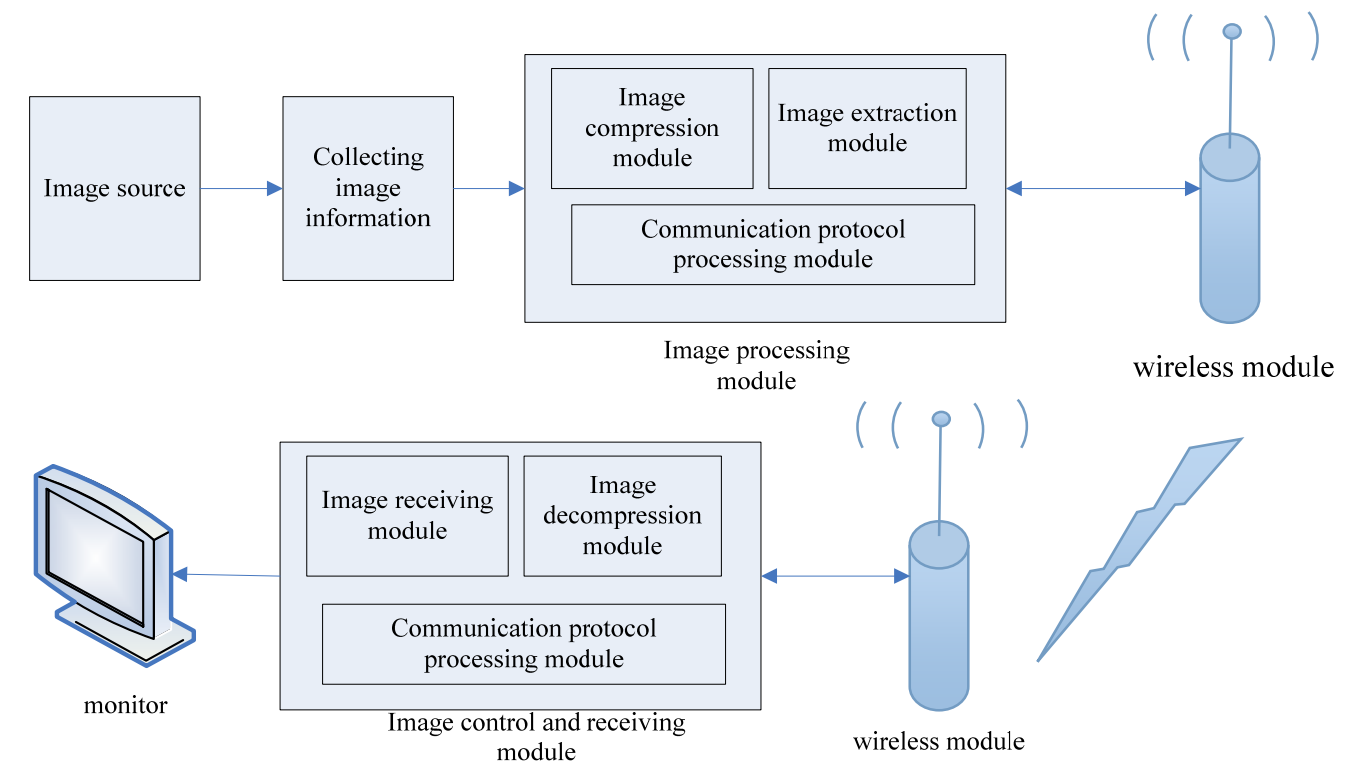

Figure 3 the design figure of visual function

Camera module equipped a small high-definition camera. The image of camera is clear, delicate and vivid color. The camera with no dead angle can be regulated the angle by needs. Size of camera is $32 \mathrm{~mm} \times 32 \mathrm{~mm}$, and it weighs 13 grams which is met the requirements of small size and light weight.

Image transmission system (An Zhongwen, 2013) bases on wireless image transmission technology and application of IEEE802.11a protocol. In order to ensure the transmission quality and transmission efficiency, the image is transferred at $5.8 \mathrm{GHz}$ which makes data transmission rate up to 54Mbit/s. The image transmission achieve high-definition in the wireless network, and the delay time is less than 1s.

Image compression technology adopted in MPEG-4 image compression standard which make the image data is the clarity of the lCIF (352x288 pixels) after compression processing in wireless transmission.

In live working, camera and picture transmission system wrapped with aluminum foil which can achieve electric field shielding and make the EMC performance better.

\subsection{Multifunctional pull pin}

There are 1 types, 2 type and 3 type three kinds of common used for live working, as shown in figure, we found the following problems in the use of these three kinds of pull pin.

1) Function is simple, replacing the insulators usually take three steps to complete: pull pin, bowl 
head and recovery. At present, the use of only one pull pin clamp cannot be completed in all these steps. Usually we need to replace the different functions of the pull pins.

2) The structure in front is not reasonable. Because the structure and size of the pulling pin pliers are not reasonable, the operation is inconvenient when using it. At the same time, the front fork of the bowl is smooth, and the bowl head is easy to fall off from the bowl fork (Li Ruhu, 2010) (An Zhongwen, 2013).

3) It's not safe. Because there is no special return spring pin part, the workers are accustomed to the use of the operating lever to restore the spring pin.It's easy to cause damage to the operating rod insulation which is not safe.

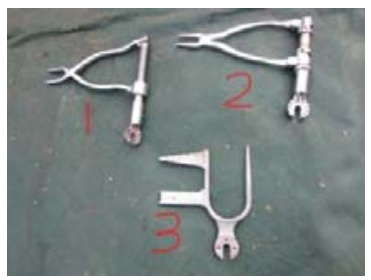

Figure 4 Commonly used pull pins in live working

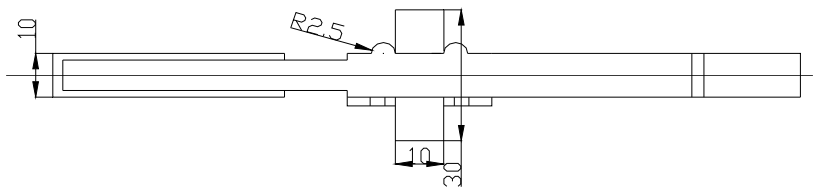

(a) Top view
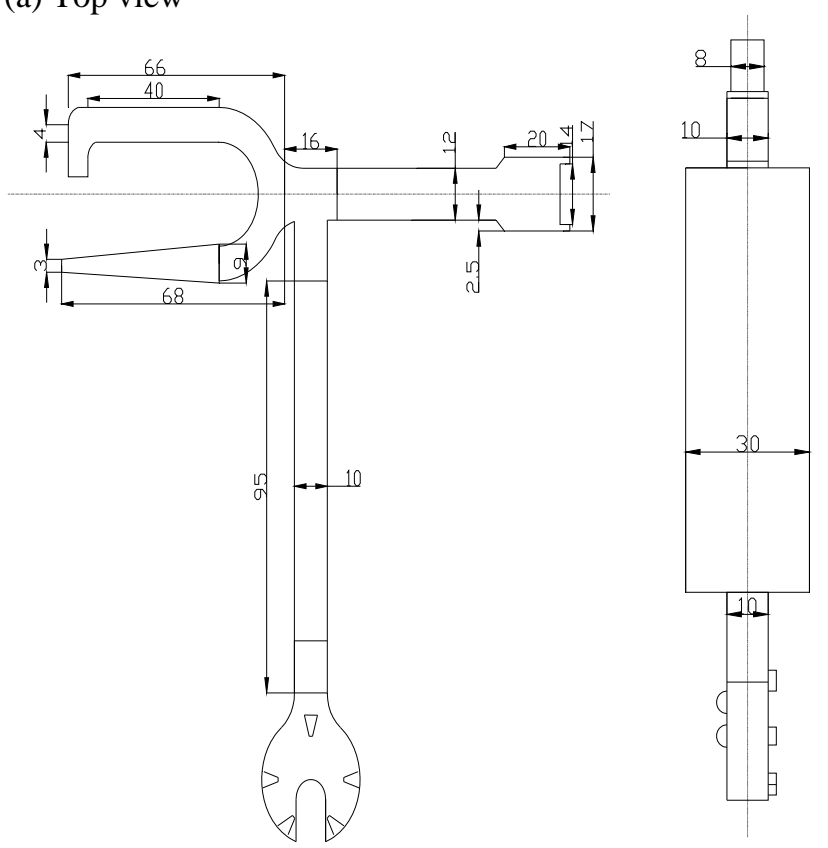

(b) Positive view figure

(c) Side view

Figure 5 Schematic diagram of the structure of multifunction pull pin

Based on the above analysis and combined with the line parameters, the design of multifunctional pull pin structure was shown in the figure 5
The end of pull pin is designed into a flat rectangular structure, which can realize the function of pulling off the pin. Because of the spring pin with a bowl head gap is less than $8 \mathrm{~mm}$, so the end of pull pin is designed into $10 \mathrm{~mm}$ wide rectangular structure which workers can launch of the insulator pins successfully.

The main axle of pull pin was designed into $10 \mathrm{~mm} \times 95 \mathrm{~mm}$ rectangular structure instead of cylindrical spindle. The insulator was pushed forward successfully and spring pin was recovered by using the rectangular structure.

The front end of the pull pin is designed into a fork shape, and the fork head is designed into a hook shape, which can effectively stabilize the bowl head and prevent the sliding out.

Universal toothed thread connection was used in connection of pull pin and control lever. The multifunctional pull pin can realize the operation of pulling off, taking a bowl head, a pin, etc., and the structure is reasonable, the universality is strong, and the requirement is satisfied.

\section{FIELD APPLICATION}

Table 1 comparison record of new and old pin function test

\begin{tabular}{lllll}
\hline & $\begin{array}{l}\text { Type } \\
1 \text { pin }\end{array}$ & $\begin{array}{l}\text { Type2 } \\
\text { pin }\end{array}$ & $\begin{array}{l}\text { Type } \\
\text { 3 pin }\end{array}$ & $\begin{array}{l}\text { Multifunctional } \\
\text { pull pin }\end{array}$ \\
\hline $\begin{array}{l}\text { Operation time } \\
\text { of 1(min) }\end{array}$ & 12 & 12 & 8 & 3 \\
$\begin{array}{l}\text { Operation time } \\
\text { of 2(min) }\end{array}$ & 8 & 8 & 8 & 3 \\
$\begin{array}{l}\text { The number of } \\
\text { operations for }\end{array}$ & 2 & 1.5 & 1.3 & 1 \\
$\begin{array}{l}\text { removing pin } \\
\text { The number of } \\
\text { operations for }\end{array}$ & 1 & 1 & 2 & 1 \\
taking out a \\
$\begin{array}{l}\text { bowl } \\
\text { The number of } \\
\text { operations for } \\
\text { mounting bowl }\end{array}$ & 1 & 1 & 3 & 1 \\
$\begin{array}{l}\text { head } \\
\text { The number of } \\
\text { operations for } \\
\text { recovering } \\
\text { spring pin }\end{array}$ & 6 & 6 & 6 & 1 \\
\hline
\end{tabular}

The worker in State Grid Hunan electric power company live working center replaces $220 \mathrm{kV}$ insulator string with live line work in April 2015.They use the multifunction control lever in the implementation of the operation. By using the multifunction control lever, the operation of pulling off, taking a bowl head, a pin can be realized.

In the course of operation, the operation time of the multifunctional operation lever was recorded and compared with that of the old, the comparison results are shown in Table 1. 
Note: 1. Operation time of 1 start from the insulation pull plate by force, the spring pin can be taken out and end of the bowl head and the insulator was separated. Operation time of 2 start from the installation of bowl and end of the spring pin was recovery.

The scene job picture is as follows
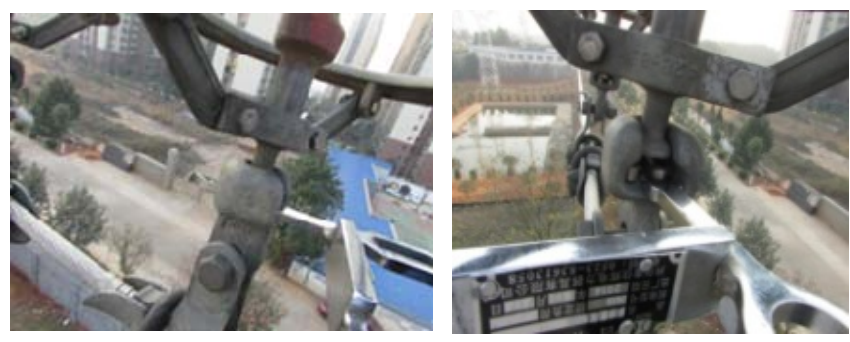

(a) pull pin

(b) remove the bowl head
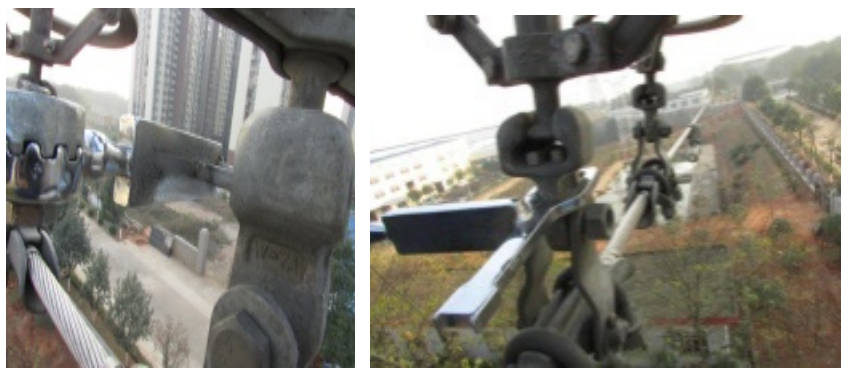

(c) push pin

(d) mounting bowl head

Figure 6 Field work

\section{CONCLUSION}

1) Combination with the engineering practice, a visual multifunction operating lever was developed, which can be used to find the dead zone of the naked eye by using the operating rod, which can realize the accurate control of the operation process.

2) The multifunction pin was developed, the operator can use the tool to accurately complete the pull, take the bowl head, the head of the assembly, the assembly and other operations, to improve the efficiency of the tool use.

3) In the field of use, the operation is flexible, easy to use, and can reduce operating time, reduce labor intensity, improve work efficiency.

\section{REFERENCES}

An Zhongwen, A scheme design for wireless image transmission [D], Beijing, 2013

DL/T878-2004, Test guide of the insulating tool for live working[S], 2004

GB/T 18037, Technical requirements design guide live working tools[S], 2003

$\mathrm{Hu}$ Tao, Hu Yi Safety protection for live working on transmission line,High Voltage Engineering[J], 2006, 30(5):22-25
$\mathrm{Hu} \mathrm{Yi}$, Live working echnology[M],Beijing, electric power press of China,2004

Li Ruhu, Live working mechanics[M] Beijing, electric power press of China,2010 